\title{
Innovation and Entrepreneurship in Engineering Education in India.
}

\author{
S. A. Khot ${ }^{1}$ \\ ${ }^{1}$ SIT. College of Engineering Ichalkaranji. (Maharashtra) India. \\ Tel. +917350542020 \\ ${ }^{1}$ sakhot.2000@gmail.com
}

\begin{abstract}
The aim of this paper is to study the nurturing of innovation and entrepreneurship among the student of engineering college in India. It also discusses the methodology used by different countries to develop the culture concerning to skills required the same. The medical education system is compared with our existing engineering education in terms of inclinations towards innovation and entrepreneurship. Different strategies are suggested to develop culture among aspirants. It is believed that synergy among all stakeholders would bring change towards innovation and entrepreneurship.
\end{abstract}

Keywords: Innovation, Entrepreneurship, Engineering education
Introduction: Technical education is the foundation of technology development. In earlier times, technical education in the country has prepared the students primarily for employment. A wide spectrum of quality exists in India, starting from those that meet the international standards to those that are not acceptable for any benchmark. Engineers must be create employment instead of becoming employment seekers.

Engineering and technology in the country have to be driven by competent engineers and scientists. The starting point has to be the quality of products. Engineering is a preferred discipline which covers almost for one fourth of the total enrolment in higher education. The annual enrolment in engineering tripled during the course of the Eleventh plan period. We have a huge set-up of engineering and technical institutions in the country. However, many of them are below the level or standard of education in the country. Academic excellence must be given to top priority. Our educational standards must be improved to match international benchmarks. Every engineering and technical institute in the country must make maximum effort to help India develop a large pool of proficiency in technical manpower.

India today is in the midst of the most exciting time and most challenging of times. The forces of technology,

modernisation, urbanisation, and our exclusive demographic benefit are shaping the future course of the country and paving the way for extraordinary development. However, as we move on this route of development and growth, we also need to be watchful that we are creating a society that is inclusive and equitable. India has a huge reserve of unmet needs in critical areas such as health, education, agriculture, energy which is depriving large sections of our populations hopeful to opportunities that would enhance future. It is in these circumstances that innovation matters in India. Innovation that can offer solutions to existing problems where traditional approaches have failed to deliver results holds the key to a more inclusive development model. It can enhance access, affordability, service delivery and improve the lives of the people at the bottom of the economic pyramid.

Innovation is the outcome of two distinct steps - firstly, the generation of an idea or invention; and secondly, the conversion of that invention into business i.e. exploitation. Invention encompasses all steps aimed at creating new ideas and getting them to work. Exploitation includes all stages of commercial development, including focusing of the ideas generated towards specific objectives, followed

\author{
S. A. $\operatorname{Khot}^{1}$ \\ ${ }^{1}$ SIT. College of Engineering Ichalkaranji. (Maharashtra) \\ India. \\ ${ }^{1}$ sakhot.2000@gmail.com
}


by evaluation of those objectives. Innovation is the key thrive in market in this age of cut-throat competition. In this cost competitive and fast pacing world where technologies and products become outdated every now and then, the companies need to devise unconventional policies and ways to expand, rather than attempting to feed the market with predicate and familiar range of new products. Companies should envisage creating breakthrough that would develop a new market or a new demography.

Entrepreneurship is the professional application of knowledge, skills and competencies and/or of monetizing a new idea, by an individual or a set of people by launching an enterprise a new or diversifying from an existing one, thus to pursue growth while generating wealth, employment and social good. The Entrepreneurship Pyramid in India [1] in terms of sectors and numbers of people engaged is made up of the following:

- Level 1: Agriculture and other activities: Crop production, Plantation, Forestry, Livestock, Fishing, Mining and Quarrying.

- Level 2: Trading services: Wholesale and retail trade; Hotels and restaurant

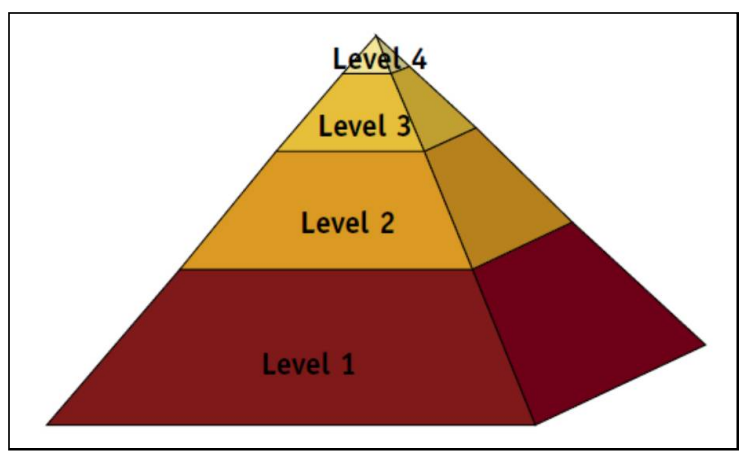

Fig. 1 Entrepreneurship pyramid

- Level 3: Old economy or traditional sectors: Manufacturing, Electricity, Gas and Water supply

- Level 4: Emerging sectors IT, Finance, Insurance and Business services, Construction, Community, Social \& Personal Services, and Supply Chain: Transport- Storage-Communications etc.

Levels 2 and 3 of the pyramid comprise the traditional areas of Entrepreneurship. Level 4, on the other hand, is an emerging/modern sector of Entrepreneurship with high growth rates. In future we may expect a broadening of Levels 3 and 4 with the activities from Levels 1 and 2 migrating to the other levels.

Entrepreneurship and Innovation are the key drivers for generating wealth from knowledge, supported principally by the availability of skilled human resources, access to finance and the ability of the State to create an enabling environment.

\section{Literature review:}

Joseph Bordogna[2] highlighted that entrepreneurs contributed a lot to US economic development. They bring technology intensive, often risky, innovations to the commercial market - and in the process, even help to develop whole new industries. Today's engineering graduates must be capable of integrating knowledge from a variety of disciplines and working with industry partners to advance that knowledge into innovations. In the larger sense, innovation depends upon a mutual, synergistic set of interactions that includes not only science, engineering and technology, but social, political and economic interactions as well. We need new arrangements that foster the kind of integration that supports innovation, and the social and economic well being it enables. If innovation is at the heart of progress, then we need to understand the skills that foster the capacity for risk taking, for imagination, and a tolerance for unfamiliar and uncertain territory. That in turn will mean that our institutions must evolve to produce these skills. Innovation and competitive entrepreneurship will always remain an enduring quest, an on-going process.

Elizabeth C. Kisenwether[3] revealed that, there is general agreement that entrepreneurial thinking and attitudes can be learned and fostered. Firstly, second year students interested in technology entrepreneurship are actively recruited from the colleges of business, engineering. Crossuniversity participation ensures diverse project teams. Within the Minor engineering students take a business basics course. This course establishes students' expertise and confidence in doing work outside their major, and appreciation of their team members' skills. Students also work on a minimum of three product/process design teams, repeatedly executing the idea-to-product viability evaluation including marketing and finance analysis, and product prototyping. Students see the value of solid team communications, creative problem solving, and tough evaluation of their solutions by non-academic judges. Secondly, during the senior year, students work on Stage I teams, either doing "starter-technology" business assessment and product prototyping researcher, or working with a local high-tech company in a new product development and launch. Stage II projects are challenging out-of-comfort-zone experiences for the students, with fixed deadlines, firm deliverables, intellectual property issues, and tough go-no go decisions.

Serge Luryi et.al [4] observed that the recent changes in the world present both challenges and opportunities to the engineering education. The practice of engineering is changing with the globalization of manufacturing, research and development. New interdisciplinary fields have come to life and traditional engineering is increasingly influenced by the information technology. Employment shifts to smaller entrepreneurial firms often located offshore. Engineering education seems poised to follow the jobs. US believe one of the most powerful answers is entrepreneurship. Not only has this been the traditional American strength, but its foundation rests on the unique advantages of their society, openness, mobility, relative absence of corruption, relative freedom from red tape, our extremely well established system of intellectual property protection and widely available venture funding structures. US student learn entrepreneurship on their own, usually well past the university stage of their careers. In our view, this must change all over, and change rapidly. This change must be reflected in the curricula, but more importantly, in 
the attitude at our academic institutions. Traditionally, courses on entrepreneurship originated in business or management schools. This began to change during the last decade when many educational institutions began to introduce entrepreneurial education in the engineering curriculum.

The MIT program [5], though open for engineering and science students, is centered at the Sloan School of Management. The Sloan School offers a wide range of courses in launching, managing, and growing technology based businesses available to engineering and science students. The courses use a variety of teaching methods: case studies, internships, guest lectures, and external reviews of student assignments by venture capitalists, and student projects. All courses involve teamwork and focus on presentation skills. As a part of the MIT program, the MIT Entrepreneurship Center was instituted in 1996 to help MIT students, alumni, and faculty to start and sustain entrepreneurial activity. It provides an array of educational programs, networking opportunities, technologies, and resources. The Center also conducts the renowned MIT Entrepreneurship Competition that is designed to encourage MIT students and researchers to act on their talent and ideas. The Competition awards money and business startup services to outstanding teams of student.

The Stanford Technology Ventures Program (STVP) [6] is hosted by the department of Management Science and engineering within Stanford University's School of Engineering. It has a strong outreach effort that includes hosting international conferences on teaching entrepreneurship. Stanford's STVP is mainly an educational program for individual students founded on the premise that in addition to technical skills, students need to know how to identify market opportunities and to take leadership roles in business. To meet this goal, the program offers both introductory and advanced courses in the field of entrepreneurial marketing, finance, strategy, and innovation. The courses range from standard academic courses for undergraduate and graduate students to large public lecture series such as the Entrepreneurial Thought Leaders, to intensive, year-long programs such as the Mayfield Fellows Program.

\section{Suggestions:}

It has been observed that, in spite of millions of students pursuing engineering education in India, outcome in terms of research, innovation and entrepreneurship is not encouraging. It reveals from the different reports that employability of engineering student has been alarming situation in the country. If we compare our engineering education with medical education, we lack in orienting students towards entrepreneurship. Medical students never think about job, since first day of admission they start dreaming about their career plan. Even it had planned at junior college itself. If we compare post graduation education of engineering and medical students we will notice huge difference in methodology. Entire medical education has been based on hands on skill development of their courses at all level and specialisation. With this I would like to suggest some point to nurture culture of innovation and entrepreneurship in engineering education. It has to be inculcated at different level of the system in the following

- Gurukul system

Engineering education should be fully residential for students and teachers. With this environment students can utilize all facilities at all times. Even academics can be scheduled as per convenience of teachers and students to impart different skills. Teachers would be available at all times to support the students. Overall development of all students is highly attainable. Even yoga, meditation can be imbibed among the student.

- Laboratories and library

State of art laboratory should be established at every department with latest instrumentations. Table mounted equipments should not be used otherwise which misleads students. College must have research centre recognised by affiliated university or any research organisation. Facility at workshop enable student to do all project work at college itself. Lab assistant at laboratories and instructors form workshop must have industrial experience and enthusiasm to support students during lab and project work. Use of laboratories and library should at the fullest extent. Students should be encouraged to use maximum possible for project and product developments.

- Curriculum philosophy

As per Bloom's taxonomy, intellectual skills and motor skills are essential component of engineering curriculum. Unfortunately, motor skills are neglected. In order to imbibe motor skills during lab practical batch size should be reduced or set of experiments has to be increased. Industrial training has to increase from first year to final year in their interested area. Internship is to make compulsory for third year students which would help final year projects. University affiliated colleges should add content beyond syllabus in order to enrich course. Curriculum philosophy has to be penetrated among faculty and students and other stakeholders. Innovation and entrepreneurship has to be introduced in the syllabus from first year to final year in progressive manner. So that student will get feel of pleasure of learning towards the goal.

- Faculty Empowerment

Faculty in the engineering education is the backbone of the system, unfortunately neglected in the system. Faculty dignity must be maintained. In order to nurture the conductive environment for innovation and entrepreneurship among students, faculty initially oriented towards it. Faculty must be empowered with decisions about their lab development. They should be given sufficient funding as seed money during start ups and further support as per their genuine requirements. They should motivate for $\mathrm{PhD}$ and post $\mathrm{PhD}$ research work. They should be encouraged to publish research papers at journals and conferences at national and international level in order to get exposure to research community. Those faculty contributing more towards innovation and building 
entrepreneurship among student be rewarded and their academic load can be proportionally reduced.

- Student enrichment

Student from first year should be oriented towards innovation and entrepreneurship. As per the inclinations of the student they would send for training in order to understand the business plan of entrepreneur. Further students will ask to prepare business plan of their choice with financial and marketing considerations. Student counselling towards becoming entrepreneurship is essential from first year onwards. Family background, family business if any, work culture has to be considered. Sometimes student are not interested to continue their family business, the reason for the same has to be understood. Even students should encourage to focus on the need at local level and starting of entrepreneurship for the employment of local workforce.

In order to imbibe innovation among student, they should assign the task related to, creating new knowledge, generating technical ideas aimed at new and enhanced products, manufacturing processes, as well as services, developing those ideas into working prototypes, and finally transferring them into manufacturing, distribution, and use by mankind at large.

Students should encourage to present, exhibit their ideas in different competitions, exhibitions, seminars and workshops at national and international. They should motivate to visit and interact with successful entrepreneurs to study and understand their career path, challenges faced by them. They should also cultivate habit to understand financial marketing strategies by networking.

\section{- $\quad$ AICTE/DTE}

Apex body and directorate of technical education are working hard for quality of technical education. Now time has come to focus more on innovation, entrepreneurship, research and development. In India most of the engineering colleges are running on self finance mode, in spite of intense desire of setting state of art laboratory and library unable to do due financial constraints. AICTE can establish such infrastructure initially at district level which can use by all stakeholders. Further they can identify colleges on the basis of their contribution towards innovation, R\&D work, can be financially supported to establish state of art laboratory. Competitions would be arranged at different levels such as university, state, national and international in order to showcase their hidden talent. Best innovative ideas encouraged for patenting and can be commercialized

\section{Concluding remarks:}

Holistic approach towards innovation and entrepreneurship are important components in engineering education for the overall development of students. I feel, if stakeholders decide to work in synergy with the focused goal of imbibing innovation and entrepreneurship culture among aspirants, we would notice massive change in coming years. But continuous effort and follow up is must. It would be in line with the 'Make in India' concept of our Honourable Prime Minster of Narendra Modi. It could be the right march towards the transformation of our great country India into developed nation.

\section{Reference:}

1Entrepreneurship in India- National knowledge commission, 2008

2.Joseph Bordogna Importance of Entrepreneurs to the U.S. Economy ,National Science Foundation

http://dc.engcon_ntl.org/teaching/3

3.Elizabeth C. Kisenwether,Pennsylvania State University

Moving Students with Entrepreneurial Mindsets to Being

Technology Entrepreneurs

http://dc.engcon_ntl.org/teaching/18

4. Serge Luryi, Wendy Tang, Nadia Lifshitz, Gerrit Wolf, Simona Doboli, Joseph A. Betz, Peter Maritato, and Yacov Shamash Entrepreneurship in Engineering Education 37th ASEE/IEEE Frontiers in Education Conference, October 10 - 13, 2007, Milwaukee, WI

5. The MIT 50K-Competition website: http://www.mit50k.net/.

6. The Stanford Technology Ventures Program http://stvp.stanford.edu 